\title{
Why is the principle of "as much radicality as needed, as much organ preservation as possible" only insufficiently implemented in daily practice in the surgical treatment of penile cancer patients?
}

\author{
Matthias May ${ }^{1}$, Michael Rink ${ }^{2}$, Axel S. Merseburger ${ }^{3}$, Sabine D. Brookman-May ${ }^{4,5}$ \\ ${ }^{1}$ Department of Urology, St. Elisabeth-Hospital, Straubing, Germany; ${ }^{2}$ Department of Urology, University Medical Center Hamburg-Eppendorf, \\ Hamburg, Germany; ${ }^{3}$ Department of Urology, University Hospital Schleswig-Holstein, Luebeck, Germany; ${ }^{4}$ Department of Urology, Ludwig- \\ Maximilians University, Campus Grosshadern, Munich, Germany; ${ }^{5}$ Janssen Research and Development Oncology, Los Angeles, CA, USA \\ Correspondence to: Prof. Dr. Matthias May. Department of Urology, St. Elisabeth-Hospital Straubing, Brothers of Mercy Hospital, Straubing, \\ Germany. Email: matthias.may@klinikum-straubing.de. \\ Comment on: Ghahhari J, Marchioni M, Spiess PE, et al. Radical penectomy, a compromise for life: results from the PECAD study. Transl Androl \\ Urol 2020;9:1306-13.
}

Submitted Jun 15, 2020. Accepted for publication Aug 17, 2020.

doi: $10.21037 /$ tau-20-1152

View this article at: http://dx.doi.org/10.21037/tau-20-1152

With great interest we have read the recent article by Ghahhari et al. reporting the results of a study on 72 patients with radical penectomy (1). The study group was part of a data sample of 425 patients with primary surgical treatment of penile cancer $(\mathrm{PeCa})$ during the time period 2010 to 2016; data was compiled from 13 European and American centers as part of the PEnile Cancer ADherence (PECAD) study. There are several reasons why the results reported by Ghahhari et al. are important; apparently two points must be outlined here: (I) the study represents one of the largest series on PeCa-patients with radical penectomy, (II) reported data represents real-world evidence, since not only specialized centers for the treatment of $\mathrm{PeCa}$ were included. The management of $\mathrm{PeCa}$-patients in daily routine practice is often inconsistent with guidelines recommendations (2). This finding can be confirmed par excellence through the data presented by Ghahhari et al:: in the study cohort, $43.1 \%$ of the patients (31/72) undergoing maximum-ablative local therapy had a tumor stage pT1-2, and $30.6 \%$ of these high-risk $\mathrm{PeCa}$ had a $\mathrm{pNx}$ lymph node stage (thus no inguinal lymph-node-dissection took place) (1). Even considering that the primary surgical therapy in these patients took place 4-10 years ago and that-when the TNM-classification 2009 was appliedpT2 was classified as infiltration of the corpora cavernosa, it is appropriate to state that also during this time period radical penectomy was not the guideline-recommended primary surgical approach for $\mathrm{PeCa}$ in local tumor stages pT1-2 (2). The ultimate goal of treating penile cancer is long-term survival while maintaining quality-of-life. Sufficient radicality must therefore be sought concomitant with organ preservation as far as feasible. The principle therefore applies: as much radicality as needed, as much organ preservation as possible (3). Tumor-free surgical margins are important; to address this aspect, in locally advanced tumors partial penectomy and rarely radical penectomy are justified (3). Organ-preserving surgery (OPS) is currently the therapy recommended by guidelines for all pT1 tumors and also for the majority of pT2 tumors, although this approach may result in a higher rate of local recurrences compared to partial or radical penectomy, while not compromising survival (2-4). The comparably positive impact of OPS on postoperative quality of life has been demonstrated in various studies (5).

Even if the European guidelines on $\mathrm{PeCa}$ do not show evidence level 1 as a basis for their recommendations for primary surgical therapy, the guidance provided is more than just a useful decision-making corridor (2). For example, in another work by the PECAD study, Cindolo et al. demonstrated that adherence (compared to non-adherence) to guidelines recommendations for primary surgical tumor management resulted in a $60 \%$ decrease in overall mortality (HR MULTIVARIAT $0.40, \mathrm{P}=0.014$ ) (6).

Basically, there are two different methodological 
Table 1 Multivariate binary-logistic regression model for the analysis of independent criteria, which in a cohort of 557 urologists predict the answer "partial penectomy" to the question asked about the preferred local therapy for penile cancer in clinical stage T1

\begin{tabular}{|c|c|c|c|}
\hline Predictor & n (\%) or median (IQR) & OR $(95 \% \mathrm{Cl})$ & $\mathrm{P}$ \\
\hline $\begin{array}{l}\text { Leading position [head or senior physician] (vs. residents and } \\
\text { board-certified urologists) }{ }^{\star \star}[n=554]\end{array}$ & 206 (37.2\%) vs. 348 (62.8\%) & $0.37(0.22-0.65)$ & $<0.001$ \\
\hline Number of PeCa-patients treated in 2017 , cont. ${ }^{*}$ & $5[3-8]$ & $0.89(0.84-0.94)$ & $<0.001$ \\
\hline Number of urologists in the department, cont.* & $14[10-18]$ & $1.04(0.99-1.10)$ & 0.079 \\
\hline Respondent carries out PeCa surgery independently ${ }^{\star \star}[n=556]$ & 247 (44.4\%) vs. 309 (55.6\%) & $2.00(1.19-3.37)$ & 0.009 \\
\hline Germany (vs. outside Germany) ${ }^{*}$ & $34(75.6 \%)$ vs. $11(24.4 \%)$ & $1.33(0.83-2.14)$ & 0.238 \\
\hline
\end{tabular}

${ }^{*}$, refers to the 45 departments involved; ${ }^{*}$, refers to the 557 participating urologists. Cl, confidence interval; cont., continuously; IQR, interquartile range; OPS, organ-preserving surgery; $\mathrm{PeCa}$, penile cancer.

scientific approaches to check the adherence to guideline recommendations in PeCa therapy management. Real world evidence can be retrieved from patient series and it can be retrospectively analyzed to what extent treatment patterns follow guidelines recommendations applicable during the therapy period (6,7). Alternatively, cross-sectional survey studies can be conducted to get feedback from urologists on specific case scenarios to determine their preferred therapy and to check their adherence to current guidelines.

The second approach was applied by the E-PROPS (European PROspective Penile Cancer Study) project, an international collaborative group evaluating the therapeutic management for PeCa in Central Europe. The E-PROPS project has conducted a survey which was sent to 45 European centers and distributed among urologists in the third quarter of 2018 (Germany $n=34$, Austria $\mathrm{n}=8$, Switzerland $\mathrm{n}=2$, Italy $\mathrm{n}=1$ ). In total, 557 urologists participated in the survey; $43.5 \%$ of responders were residents $(8,9)$. The E-PROPS questionnaire consisted of 14 questions assessing (I) the position of urologists in their department, (II) their personal responsibilities in $\mathrm{PeCa}$ therapy-management, (III) their individual knowledge on $\mathrm{PeCa}$, (IV) information about clinic-specific workflow regarding PeCa-patients, and (V) the therapeutic management of PeCa-patients (primary surgery, lymph node dissection, chemotherapy) in the participating urological department. Additional information on clinicspecific confounders was also collected.

The methods applied in the E-PROPS survey will be illustrated below using a concrete example. One question about a given case scenario was as follows: "What kind of local treatment would a patient receive in your clinic if he was diagnosed with penile cancer T1b locally restricted to the glans penis?" Answers given by 557 urologists were divided into given categories as follows: $A$ - laser therapy $(\mathrm{n}=3,0.5 \%), B$ resurfacing of the glans penis $(\mathrm{n}=7,1.3 \%), C$ - glansectomy (if applicable only partial) $(\mathrm{n}=309,55.5 \%), D$ - local radiotherapy (0\%), $E$ - partial penectomy $(\mathrm{n}=166,29.8 \%)$, $F$ - "I am not sure" or rather "I can (or have) the answer not given" (n=72, 12.9\%). Only answers $C$ and $D$ are covered by recommendations of the EAU-guideline (309/557, $55.5 \%$ ) (2). However, almost $30 \%$ of responding urologists preferred the option $E$ of non-OPS treatment partial penectomy, which is completely incongruent with current guidelines recommendations for this scenario. By building a multivariate binary-logistic regression model with the endpoint partial penectomy, heads of departments or senior physicians and a higher number of treated PeCa-patients in the department reached the endpoint significantly less often (Table 1). Paradoxically, self-responsible PeCa surgery reported by the respondent led to a doubling of this end point (OR 2.00, $\mathrm{P}=0.009)$. Interestingly, no significant impact was seen for academic status of the hospital and size of department (number of beds, number of urologists employed) (Table 1).

Based on the results of the extremely important work by Ghahhari et al. as well as the E-PROPS data, it is clearly justified to state that we need strategies to further improve 
the adherence to guidelines. These include specific training for surgeons and urologists and the formation of superregional networks with a multidisciplinary approach that will likely favor high-volume and specialized centers $(1,6,10)$. We would like to end this letter following the words of Georg Christoph Lichtenberg, a German scientist and philosopher of the 18th century: "We cannot predict whether things will get better if they change; but things need to change ultimately if the goal is improvement."

\section{Acknowledgments}

Funding: None.

\section{Footnote}

Provenance and Peer review: This article was commissioned by the editorial office, Translational Andrology and Urology. The article did not undergo external peer review.

Conflicts of Interest: The authors have completed the ICMJE uniform disclosure form (available at http://dx.doi. org/10.21037/tau-20-1152). MR serves as an unpaid Associate Editor-in-Chief of Translational Andrology and Urology from January 2020 to December 2021. The other authors have no conflicts of interest to declare.

Ethical Statement: The authors are accountable for all aspects of the work in ensuring that questions related to the accuracy or integrity of any part of the work are appropriately investigated and resolved.

Open Access Statement: This is an Open Access article distributed in accordance with the Creative Commons Attribution-NonCommercial-NoDerivs 4.0 International License (CC BY-NC-ND 4.0), which permits the noncommercial replication and distribution of the article with the strict proviso that no changes or edits are made and the original work is properly cited (including links to both the formal publication through the relevant DOI and the license). See: https://creativecommons.org/licenses/by-nc-nd/4.0/.

\section{References}

1. Ghahhari J, Marchioni M, Spiess PE, et al. Radical penectomy, a compromise for life: results from the
PECAD study. Transl Androl Urol 2020;9:1306-13.

2. Hakenberg OW, Compérat EM, Minhas S, et al. EAUguidelines on penile cancer: 2014 update. Eur Urol 2015;67:142-50.

3. Roiner M, Maurer O, Lebentrau S, et al. Management of penile cancer patients: new aspects of a rare tumour entity. Aktuelle Urol 2018;49:242-9.

4. Lindner AK, Schachtner G, Steiner E, et al. Organsparing surgery of penile cancer: higher rate of local recurrence yet no impact on overall survival. World J Urol 2020;38:417-24.

5. Kamel MH, Bissada N, Warford R, et al. Organ Sparing Surgery for Penile Cancer: A Systematic Review. J Urol 2017;198:770-9.

6. Cindolo L, Spiess PE, Bada M, et al. Adherence to EAU-guidelines on penile cancer translates into better outcomes: a multicenter international study. World J Urol 2019;37:1649-57.

7. Mistretta FA, Mazzone E, Palumbo C, et al. Adherence to guideline recommendations for lymph node dissection in squamous cell carcinoma of the penis: Effect on survival and complication rates. Urol Oncol 2019;37:578.e11-9.

8. Distler FA, Pahernik S, Gakis G, et al. Adherence to the EAU-guideline recommendations for systemic chemotherapy in penile cancer: results of the E-PROPS study group survey. World J Urol 2020;38:2523-30.

9. Suarez-Ibarrola R, Zengerling F, Haccius $M$, et al. Adherence to European Association of Urology and National Comprehensive Cancer Network Guidelines Criteria for Inguinal and Pelvic Lymph Node Dissection in Penile Cancer Patients-A Survey Assessment in Germanspeaking Countries on Behalf of the European Prospective Penile Cancer Study Group. Eur Urol Focus 2020;S24054569(20)30061-4.

10. Vanthoor J, Thomas A, Tsaur I, et al. Making surgery safer by centralization of care: impact of case load in penile cancer. World J Urol 2020;38:1385-90.

Cite this article as: May M, Rink M, Merseburger AS, Brookman-May SD. Why is the principle of "as much radicality as needed, as much organ preservation as possible" only insufficiently implemented in daily practice in the surgical treatment of penile cancer patients? Transl Androl Urol 2020;9(5):1901-1903. doi:10.21037/tau-20-1152 